\title{
The L2/HNK-1 Carbohydrate Is Preferentially Expressed by Previously Motor Axon-associated Schwann Cells in Reinnervated Peripheral Nerves
}

\author{
R. Martini, ${ }^{1}$ M. Schachner, ${ }^{1}$ and T. M. Brushart ${ }^{2}$ \\ ${ }^{1}$ Department of Neurobiology, Swiss Federal Institute of Technology, Hönggerberg, 8093 Zürich, Switzerland, and ${ }^{2}$ The \\ Raymond Curtis Hand Center Union Memorial Hospital, and the Departments of Orthopaedics and Neurology, Johns \\ Hopkins University, Baltimore, Maryland
}

\begin{abstract}
The carbohydrate epitope L2/HNK-1 (hereafter designated L2) is expressed in the adult mouse by myelinating Schwann cells of ventral roots and muscle nerves, but rarely by those of dorsal roots or cutaneous nerves. Since substrate-coated L2 glycolipids promote outgrowth of cultured motor but not sensory neurons, L2 may thus influence the preferential reinnervation of muscle nerves by regenerating motor axons in vivo. In the present study, we have analyzed the influence of regenerating axons on $\mathrm{L} 2$ expression by reinnervated Schwann cells by directing motor or sensory axons into the muscle and cutaneous branches of femoral nerves of 8-weekold mice. We observed that regenerating axons from cutaneous branches did not lead to immunocytochemically detectable $\mathrm{L} 2$ expression in muscle or cutaneous nerve branches. Axons regenerating from muscle branches led to a weak L2 expression by few Schwann cells of the cutaneous branch, but provoked a strong L2 expression by many Schwann cells of the muscle branch. Myelinating Schwann cells previously associated with motor axons thus differed from previously sensory axon-associated myelinating Schwann cells in their ability to express $L 2$ when contacted by motor axons. This upregulation of L2 expression during critical stages of reinnervation may provide motor axons regenerating into the appropriate, muscle pathways with an advantage over those regenerating into the inappropriate, sensory pathways.
\end{abstract}

[Key words: regeneration, Schwann cell, peripheral nerve, motoneuron, myelin, carbohydrates, pathway specificity]

When a peripheral nerve is lesioned, denervated Schwann cells proliferate and change their morphological and molecular characteristics (Jessen and Mirsky, 1992). For example, previously myelin-forming Schwann cells lose their myelin sheaths and reexpress molecules normally confined to immature and nonmyelinating Schwann cells of newborn and adult animals, respectively (Nieke and Schachner, 1985; Martini and Schachner,

\footnotetext{
Received Feb. 22, 1994; revised May 4, 1994; accepted May 26, 1994.

We are grateful to Philipp Kessens for surgical preparations, Simone Kasper for skillful technical assistance, and Jürgen Holm and Marcus Fruttiger for introduction into the IBAS and STATView program, respectively. We are indebted to Dr. Wolfgang Härtig, University of Leipzig (Germany), for biotinylating the monoclonal antibody to L2. Our work was supported by the Curtis Research Fund (T.M.B.).

Correspondence should be addressed to Rudolf Martini at the above address. Copyright @ 1994 Society for Neuroscience $0270-6474 / 94 / 147180-12 \$ 05.00 / 0$
}

1986, 1988; for review, see Jessen and Mirsky, 1992; Martini, 1994). Such molecules include the cytoskeletal component GFAP, the low-aflinity nerve growth factor receptor, and the adhesive, neurite outgrowth-promoting cell surface molecules Ll and N-CAM (Nieke and Schachner, 1985; Martini and Schachner, 1988; for review, see Jessen and Mirsky, 1992; Martini, 1994). Another lesion-induced neurite outgrowth-promoting molecule is the extracellular matrix component tenascin, which is strongly upregulated after nerve injury by both myelinating and nonmyelinating Schwann cells (Martini et al., 1990; Fruttiger et al., unpublished observations).

Lesion-induced changes including upregulation of nerve growth-promoting molecules by Schwann cells appear to be important prerequisites for Schwann cell-mediated axonal regrowth (see Martini, 1994, for review). Support for this hypothesis is provided by the demonstration of Bedi et al. (1992) that neurons cultured from adult animals fail to extend significant axonal sprouts on cryosections of normal sciatic nerve, while outgrowth is vigorous on cryosections of predegenerated nerve. Furthermore, in the mouse mutant C57B16 OLA (Lunn et al., 1989) lesion-induced myelin degeneration and upregulation of L1 and N-CAM are retarded (Fruttiger and Martini, unpublished observations) and motor axons regenerate in abnormal association with nonmyelinating Schwann cells (Brown et al., 1991, 1992), the only Schwann cells that express L1 and N-CAM in the uninjured adult nerve (Martini and Schachner, 1986). Denervated Schwann cells also normally reacquire the ability to ensheathe axons and to myelinate those of larger caliber. This ability may depend on Schwann cell-related L1 reexpression, since antibodies to $\mathrm{L} 1$ block ensheathment and myelination in vitro (Seilheimer et al., 1989; Wood et al., 1990).

Denervated Schwann cells exhibit a high degree of phenotypic plasticity, suggesting that the Schwann cell phenotype is a passive reflection of axonal properties. Schwann cells originally associated with thin, unmyelinated axons form myelin when reinnervated by axons of larger caliber. Conversely, Schwann cells that have previously myelinated large-caliber axons do not form myelin when reinnervated by thin axons, but acquire the typical phenotype of nonmyelinating Schwann cells (Weinberg and Spencer, 1975; Aguayo et al., 1976a,b). Another example of axonal influence on Schwann cell phenotype is provided by the C57Bl6 OLA mouse, in which Wallerian degeneration is retarded (see above). This retardation is no longer observed when Schwann cells from OLA mice are reinnervated by axons from wild-type animals. Conversely, Schwann cells from wild- 
type animals can be rescued from lesion-induced degeneration when innervated by axons from OLA mice (Glass et al., 1993). The preferential expression of the $\mathrm{L} 2 / \mathrm{HNK}-1$ carbohydrate epitope (hereafter designated L2) by Schwann cells of ventral spinal roots and muscle nerves, but not of dorsal roots and cutaneous sensory nerves, may be another example of axonal influence on Schwann cell phenotype (Martini et al., 1988; 1992).

The experiments described in the present study reveal that Schwann cells are not always passive partners in axon-Schwann cell relationships. Schwann cells of the cutaneous branch of the femoral nerve of adult mice, which are normally L2 negative, hardly express $\mathrm{L} 2$ when confronted with regrowing motor axons after lesioning. In contrast, L2 is dramatically reexpressed when motor axons reinnervate Schwann cells of the muscle branch. Schwann cclls previously associated with motor axons thus appear to differ from previously sensory axon-associated Schwann cells in their ability to express L 2 when contacted by motor axons.

\section{Materials and Methods}

\section{Surgical procedures}

Experiments were performed on the femoral nerves of young adult ICR or $\mathrm{C} 57 \mathrm{Bl} / 6$ mice (2-6 months old). No strain-related difference in $\mathrm{L} 2$ expression could be detected, so these mice were used interchangeably. Intraperitoneal injection of Nembutal $(70 \mathrm{mg} / \mathrm{kg})$ or chloral hydrate $(40$ $\mathrm{mg} / \mathrm{kg}$ ) provided anesthesia. The femoral nerve was chosen because motor and sensory axons intermingle in the proximal femoral trunk, but segregate distally into discrete muscle and cutaneous branches (Brushart, 1988). Nine experimental groups were prepared (Fig. 1). In the unilaterally deefferented or deafferented groups (DE and DA, respectively), the femoral nerve was deprived of motor and sensory innervation to produce a pure sensory or pure motor nerve. Hemilaminectomy from lumbar segments $1-4$ provided exposure to the roots contributing to the femoral nerve. In DE animals, ventral roots of lumbar segments $1-4$ were transected and reflected out of the spinal canal to prevent regeneration (lumbar segment 1 contributes to motor, but not sensory innervation of the mouse femoral nerve). In the DA group, dorsal root ganglia (DRG) of lumbar segments $2-4$ were gently separated from the underlying ventral root and excised. Excision of DRG was less difficult in mice than in rats, where severe damage to ventral roots has been documented (Peyronnard et al., 1986; Schmalbruch, 1986). A group of DA animals also underwent simultaneous transection and repair of the proximal femoral nerve (DA-PR) allowing only motor axons to reinnervate both cutaneous and muscle branches. In these animals, the inguinal ligament was cut and the peritoneum reflected to expose the proximal part of the nerve, where axons destined for cutaneous and muscle branches intermingle. The nerve was transected 5 $\mathrm{mm}$ proximal to the bifurcation, and the ends were sewn together using 11-0 nylon (Ethilon) under 20-40 $\times$ magnification provided by a Zeiss Opmi- 6 operating microscope. Because of the small diameter of the nerve, a silicon tube splint (Dow Corning; 0.012 i.d.) was placed around the repair to maximize distal stump reinnervation and then removed at 2 weeks to avoid late constriction of the repair.

The remaining groups involved manipulation of the femoral nerve alone (Fig. 1). In the proximal repair (PR) and proximal repair, targetblocked (PR-B) groups the proximal femoral nerve trunk was lesioned and repaired as described above. In the PR-B group, the distal muscle branch was transected at the level of muscle innervation, doubly ligated, and sewn within a blind-ending, silicon tube to prevent regenerating axons from making contact with end organs. The cutaneous branch was similarly blocked an equal distance from the femoral nerve bifurcation. In the distal repair (DR) group, the femoral cutaneous and muscle branches were individually transected $5 \mathrm{~mm}$ distal to the bifurcation and repaired within silicon tube splints. In the distal repair, reversed group (DR-R), the orientation of these repairs was reversed (proximal muscle to distal cutaneous, distal cutaneous to proximal muscle branch). The final two groups involved removal of femoral cutaneous and muscle branches from one leg and their insertion into the contralateral femoral nerve as grafts. In the graft $(\mathrm{G})$ group, branches were grafted homotopicly, with muscle and cutaneous nerve graft inserted in the muscle or cutaneous branch, respectively. In the reversed graft group ( $G-R)$, the grafts were inserted heterotopicly, with the cutaneous nerve graft in the muscle branch and the muscle nerve graft in the cutaneous branch. Graft lengths varied from 3 to $10 \mathrm{~mm}$, and survival after surgery varied from 4 to 16 weeks.

To determine the number of motor and sensory neurons contributing to the muscle and cutancous branches in nonoperated micc and to evaluate the adequacy of DE and DA preparations, eight unlesioned femoral nerves were double labeled with horseradish peroxidase (HRP) on one branch and fluoro-gold (FG) on the other (Brushart, 1990). Cross sections ( $40 \mu \mathrm{m}$ thick) of spinal cord and DRG were examined to determine the number of neurons projecting into each branch. The cutaneous and muscle branches of four DE and eight DA animals were similarly exposed to determine the number of neurons with surviving projections to the femoral nerve.

\section{Antibodies}

Production and purification of monoclonal antibodies from rat to the L2 carbohydrate epitope have been described (Kruse et al., 1984; Fahrig et al., 1990). For immunoelectron microscopic localization of $L 2$ by the preembedding procedure (see below), antibodies were biotinylated by Dr. W. Härtig (Leipzig, Germany) according to the protocol of Bieber (1988). Production and purification of polyclonal antibodies from rabbit to mouse L1 has been described (Rathjen and Schachner, 1984; Martini and Schachner, 1986). Polyclonal antibodies from rabbit to neurofilament were obtained from Sigma (St. Louis, MO).

For indirect immunofluorescence, polyclonal antibodies were visualized by fluorescein isothiocyanate-coupled antibodies to rabbit IgG (Dako, Hamburg, Germany) or, in the case of double immunofluorescence, to tetramethyl rhodamine isothiocyanate-coupled antibodies to rabbit IgG (Dako, Hamburg, Germany). Monoclonal antibodies from rat were visualized by fluorescein isothiocyanate-coupled antibodies to rat IgG (Dako, Hamburg, Germany). For immunoelectron microscopy according to the postembedding procedure, antibodies to rat IgGs coupled to $15 \mathrm{~nm}$ gold particles (Janssen Pharmazeutica, Beerse, Belgium) were used to visualize monoclonal antibodies to $L 2$. For preembedding procedures, the biotinylated antibody to $L 2$ was detected by a preformed macromolecular complex between avidin and biotinylated HRP (ABC system, Vectastain, Vector Laboratories, Burlingame, CA).

\section{Immunocytology}

Light microscopy. Indirect immunofluorescence on sections of fresh frozen femoral nerves, including negative controls with secondary antibodies only, was carried out as described previously (Martini et al., 1988, 1990; Martini and Schachner, 1991). For double immunofluorescence, diluted primary and secondary antibodies were mixed and applied sequentially. Sections were taken $2 \mathrm{~mm}$ distal to the suture line in groups DR, DR-R, G, and G-R. In the remaining groups, sections were taken $5 \mathrm{~mm}$ distal to the bifurcation of muscle and cutaneous branches.

Preembedding immunoelectron microscopy. Localization of $\mathrm{L} 2$ on vibratome sections of perfusion-fixed sciatic and femoral nerves was carried out as described previously (Martini and Schachner, 1986) with the following modifications. For better antibody penetration, concentration of DMSO was increased from $5 \%$ to $20 \%$. Biotinylated primary antibodies were used instead of nonderivatized antibodies and were detected by a preformed macromolecular complex between avidin and biotinylated HRP. Dilution and time of incubation were chosen according to the manufacturer's instructions. HRP activity was visualized by $3,3^{\prime}$-diaminobenzidine- $4 \mathrm{HCl}$ (Sigma) and $\mathrm{H}_{2} \mathrm{O}_{2}$, followed by osmification and embedding in Spurr's medium (Martini and Schachner, 1986).

Postembedding immunoelectron microscopy. Embedding of vibratome sections of perfusion-fixed sciatic nerves in Lowicryl and immunolabeling with primary and gold-coupled secondary antibodies on ultrathin sections was carried out as described (Martini et al., 1988).

\section{Quantification of L2-positive and-negative Schwann cells and morphometric analysis}

L2-positive Schwann cells were counted on immunofluorescence micrographs of cross-sectioned nerves at a magnification of $280 x$. The number of L2-negative Schwann cells was determined by subtracting 

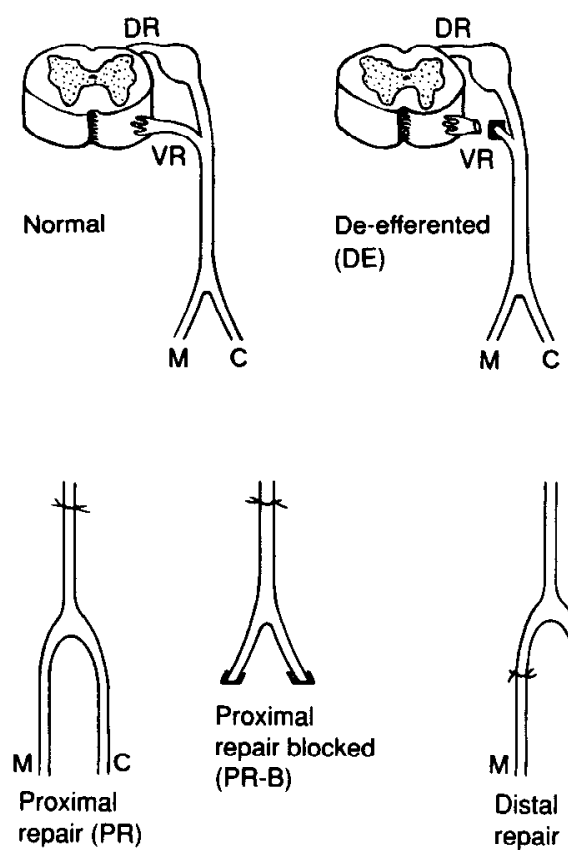
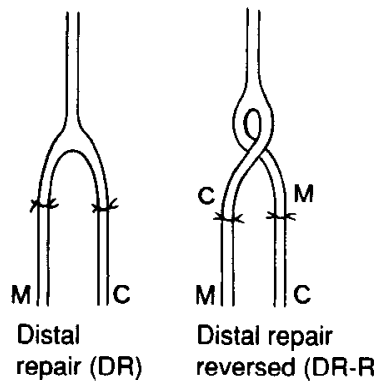
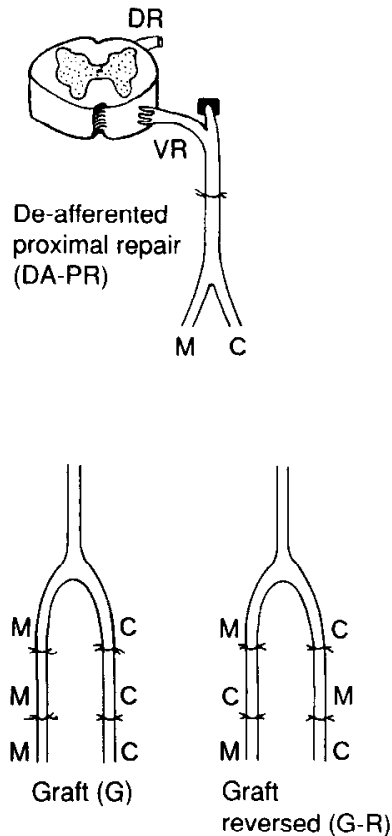

Figure 1. Experimental manipulations. Top row, The femoral nerve receives sensory axons from dorsal root ganglia (DRG) and motor axons from ventral roots. Distally, it divides into a cutaneous branch (sensory axons only) and a muscle branch (both sensory and motor axons). The femoral nerve was deefferented $(D E)$ by transection of ventral roots or deafferented $(D A)$ by removal of DRG. Proximal femoral nerve repair after deafferentation $(D A-P R)$ allowed only motor axons to regenerate into both former muscle and cutaneous Schwann cell tubes. Bottom row, Proximal repair $(P R)$ and blocked proximal repair $(P R-B)$ allowed regenerating motor and sensory axons access to both former muscle and cutaneous Schwann cell tubes, but permitted end organ contact in PR preparations only. Distal repair $(D R)$ reinnervated muscle and cutaneous branches with their normal axon populations, while reversed distal repair $(D R-R)$ reinnervated the muscle branch with cutaneous axons, and vice versa. In graft ( $G$ ) and reverse graft $(G-R)$ situations, segments of contralateral muscle and cutaneous branches were used to bridge gaps in the femoral muscle and cutaneous branches by either homo- $(G)$ or heterotopic $(G-R)$ insertion. For further details, see Materials and Methods.

L2-positive Schwann cells from the total number of Schwann cells determined on corresponding phase contrast micrographs of the nerves.

To determine axonal diameters and the ratio of axonal and fiber diameter (fiber $=$ axon plus myelin, measured at the outer cytoplasmic aspect of the myelin sheath), ultrathin sections of inserted cutaneous and distal muscle nerves (Fig. 1, G-R) were used for conventional electron microscopy. Axonal size and thickness of nerve fibers were determined on electron micrographs at $4300 \times$ using computer-assisted image analysis (IBAS). Since axons and nerve fibers are seldom round on cross sections, their diameters were determined as axonal or nerve fiber circumference, respectively, divided by $\pi$. Values were processed with the STATVIEW program and percentages of axons exceeding particular diameter value were calculated. Ratios of axonal diameter to nerve fiber diameter were calculated by dividing axonal diameters by nerve fiber diameters.

\section{Results}

Normal (= unlesioned), deafferented $(D A)$, and deefferented (DE) branches of femoral nerves

In normal, unlesioned femoral nerves of 8-week-old mice, L2 is highly expressed by Schwann cells myelinating larger-diameter axons within the muscle branch, while in the cutaneous branch myelinating Schwann cells are L2 negative (the weak L2 expression in this nerve branch is associated with a subpopulation of nonmyelinated axon-Schwann cell units; Fig. 2a, $a^{\prime}$; Martini et al., 1992). L2 immunoreactivity on myelinating Schwann cells appears thus to correlate with their association with motor axons. Muscle branches contain not only motor axons, but also large-caliber afferent (sensory) axons with thick myelin sheaths (see Peyronnard et al., 1986). If L2 expression were determined by large axonal diameter rather than by motor axon association, muscle afferent Schwann cells could also ex- press the epitope and contribute to $\mathrm{L} 2$ expression in muscle nerves (see Discussion in Martini et al., 1992). To exclude this possibility, we generated pure motor or sensory branches by excising the dorsal root ganglia (DRG) or cutting the ventral roots contributing to the femoral nerve (Fig. 1, DE, DA). Since L2-positive Schwann cells lose their immunoreactivity 2-3 weeks after denervation (Martini et al., 1992), immunohistological analysis of deafferented (DA) or deefferented (DE) femoral motor branches after 4 weeks should reveal the numbers of L2positive Schwann cells associated with motor or sensory axons, respectively.

In four DA muscle branches investigated, the pattern of L2 immunoreactivity was similar to that found in non deafferented controls (compare Fig. 2a,b). However, deafferentation reduced the number of immunoreactive Schwann cells in the muscle branch. For example, the muscle branches of two control animals contained 153 and 140 L2-positive Schwann cells, whereas the muscle branches of two DA animals contained 121 and 99 L2-positive Schwann cells. In four DE animals, ventral rhizotomy always caused a marked decrease in $\mathrm{L} 2$ immunoreactivity in the muscle branch. As revealed by double immunofluorescence with antihodies to $I .2$ and neurofilament in muscle branches of two DE animals, 174 and 208 myelinating Schwann cells around large neurofilament-positive muscle afferents were L2 negative, while only 8 and 15 were $\mathrm{L} 2$ positive and expressed the epitope more weakly than motor axon-associated Schwann cells of comparable size (Fig. $2 c$ ).

The decrease in number by 20-50 L2-positive Schwann cells after excision of DRG was greater than can be accounted for by the loss of the few L2-immunoreactive Schwann cells associated 

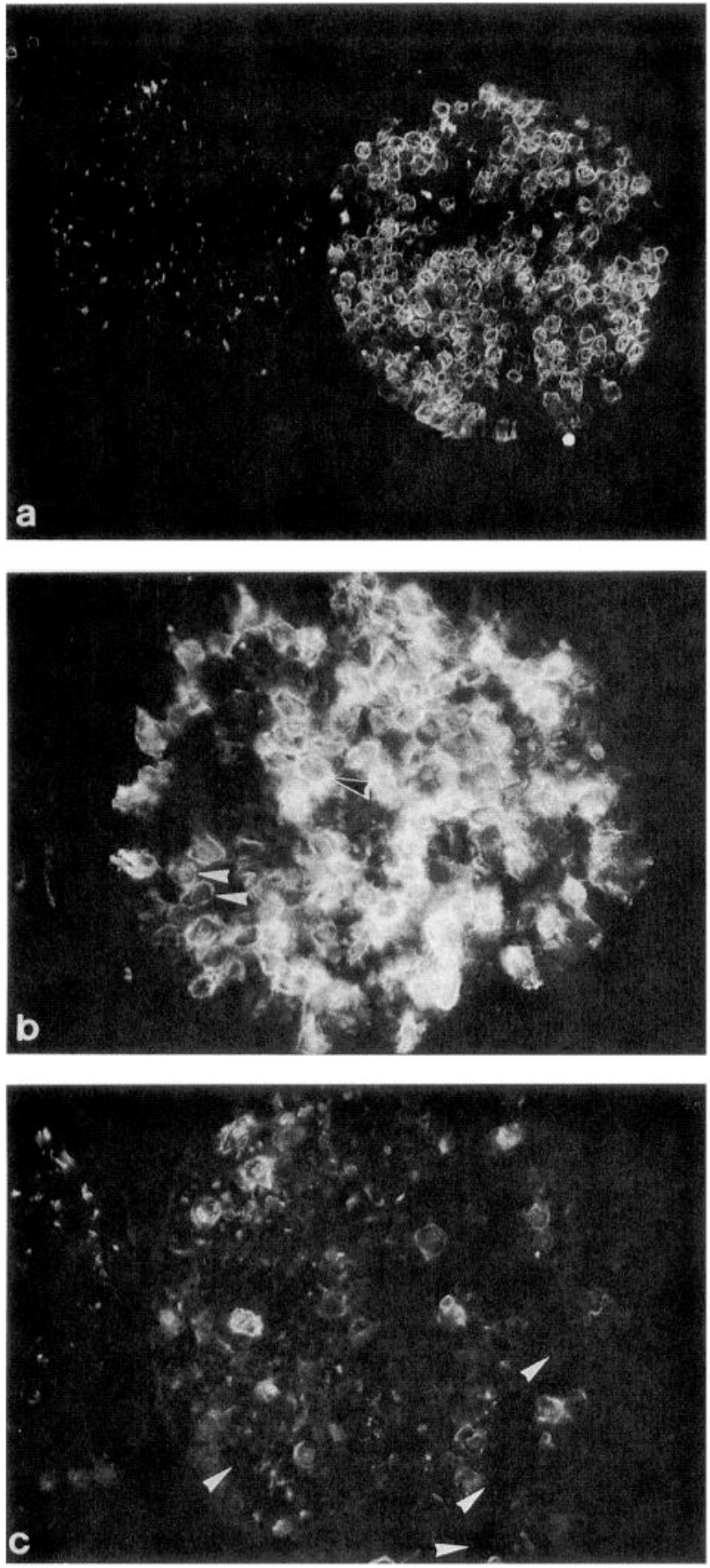
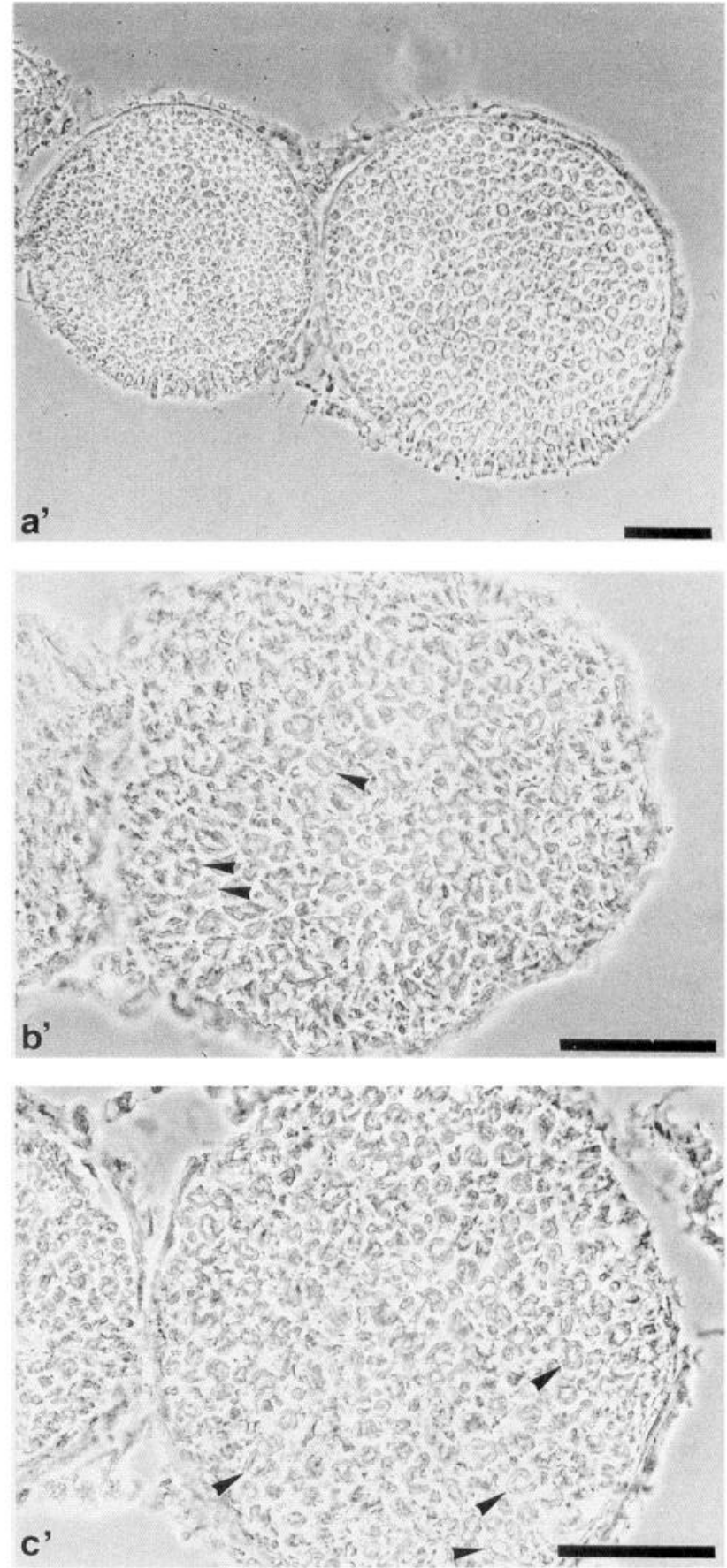

Figure 2. Immunocytological localization of L2 by indirect immunofluorescence on fresh-frozen sections of unlesioned femoral nerves ("normal"; $\left.a, a^{\prime}\right)$ and of muscle branches of deafferented (DA; $\left.b, b\right)$ and deefferented (DE; $\left.c, c\right)$ animals 4 weeks after surgery. $a$, In the muscle branch of unlesioned femoral nerves (right), myelinating Schwann cells are L2 immunoreactive, whereas in the cutaneous branch (left), they are L2 negative; L2 immunoreactivity in cutaneous nerve is associated with nonmyelinated axon-Schwann cell units. $a^{\prime}$, Phase-contrast micrograph corresponding to $a$. Muscle branch is on the right; cutaneous branch, on the left. $b, \mathrm{~L} 2$ immunoreactivity is very abundant in myelinating Schwann cells of deafferented muscle branches. The higher intensity of immunofluorescence in comparison to $a$ is most probably due to the more loosely organized endoneurium of the partially degenerating nerve that facilitates antibody penetration. Arrowheads indicate some of the immunopositive myelinating Schwann cells. $b^{\prime}$, Phase-contrast micrograph corresponding to $b$. Arrowheads point to the same myelinating Schwann cells as in $b$. $c$, L2 immunoreactivity is dramatically reduced in deefferented muscle branches. Most of the myelinating Schwann cells around large-caliber muscle afferents are L2 negative (indicated by arrowheads). The few labeled Schwann cells are predominantly of lower immunoreactivity (compare to $b$ ). $c^{\prime}$, Phasecontrast micrograph corresponding to $c$. Arrowheads point to L2-negative, myelinating Schwann cells around large-caliber muscle afferents (compare to $c$ ). Scale bars, $50 \mu \mathrm{m}$.

with muscle afferents. It is therefore conceivable that motor axons could have been damaged during excision of the overlying DRG resulting in the loss of L2 immunoreactivity of the corresponding Schwann cells. This interpretation was tested by the following control experiment. Eight animals were deafferented (DA) and double labeled using HRP and fluoro-gold $12 \mathrm{~d}$ after surgery. No neurons were labeled in the location of the removed DRG in any of the eight animals tested. However, more mo- 


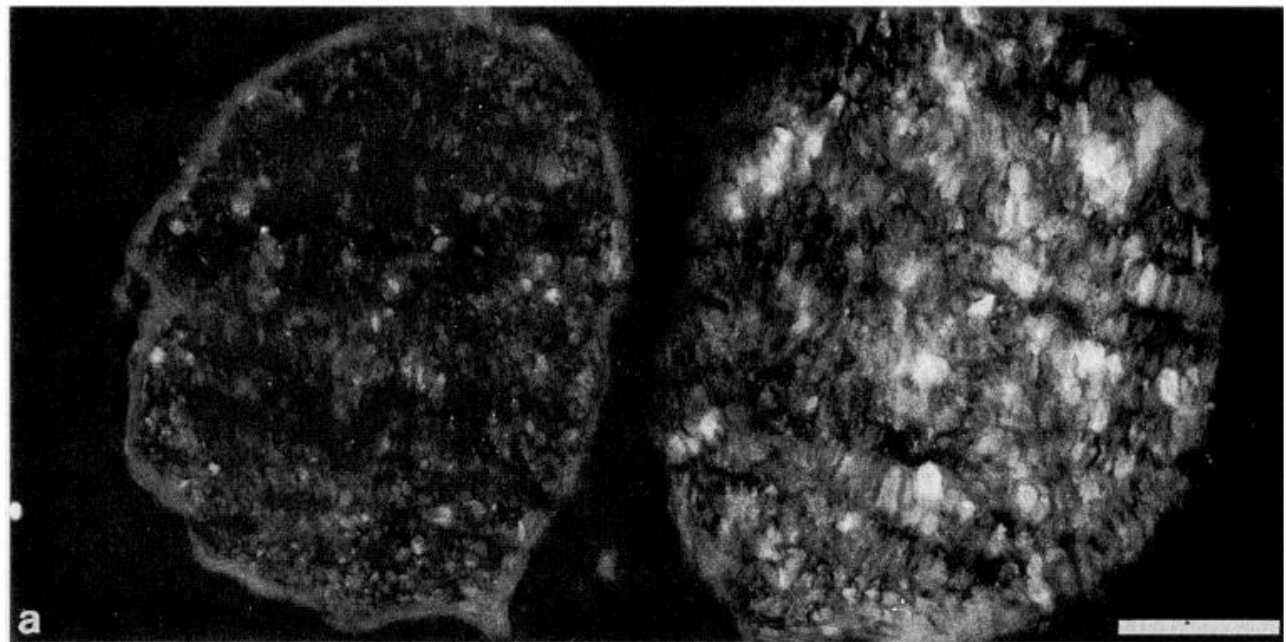

Figure 3. Immunocytological localization of $\mathrm{L} 2$ by single immunofluorescence on fresh-frozen sections of proximally repaired femoral nerves $(\mathrm{PR} ; a)$ and by double immunofluorescence of neurofilament $(b$ and $c)$ and L2 ( $d$ and $e$ ) on sections of femoral nerves from deafferented animals with simultaneous nerve repair (DA-PR; $b$-e) 4 weeks after surgery. $a$, In proximally repaired femoral nerves, L2 is associated with myelinating Schwann cells in the muscle branch (right), while the cutaneous branch (left) is almost L2 negative. $b$ and $c$, In deafferented animals, neurofilament-positive motor axons grow vigorously into both cutaneous $(b)$ and muscle $(c)$ branches after proximal nerve repair. $d$ and $e$, In the same frozen section, L2 immunoreactivity is very low in the cutaneous branch $(d)$, although motor axons are frequent (see b). By contrast, $\mathrm{L} 2$ immunoreactivity is high in the reinnervated muscle branch (e). Scale bars, $50 \mu \mathrm{m}$.
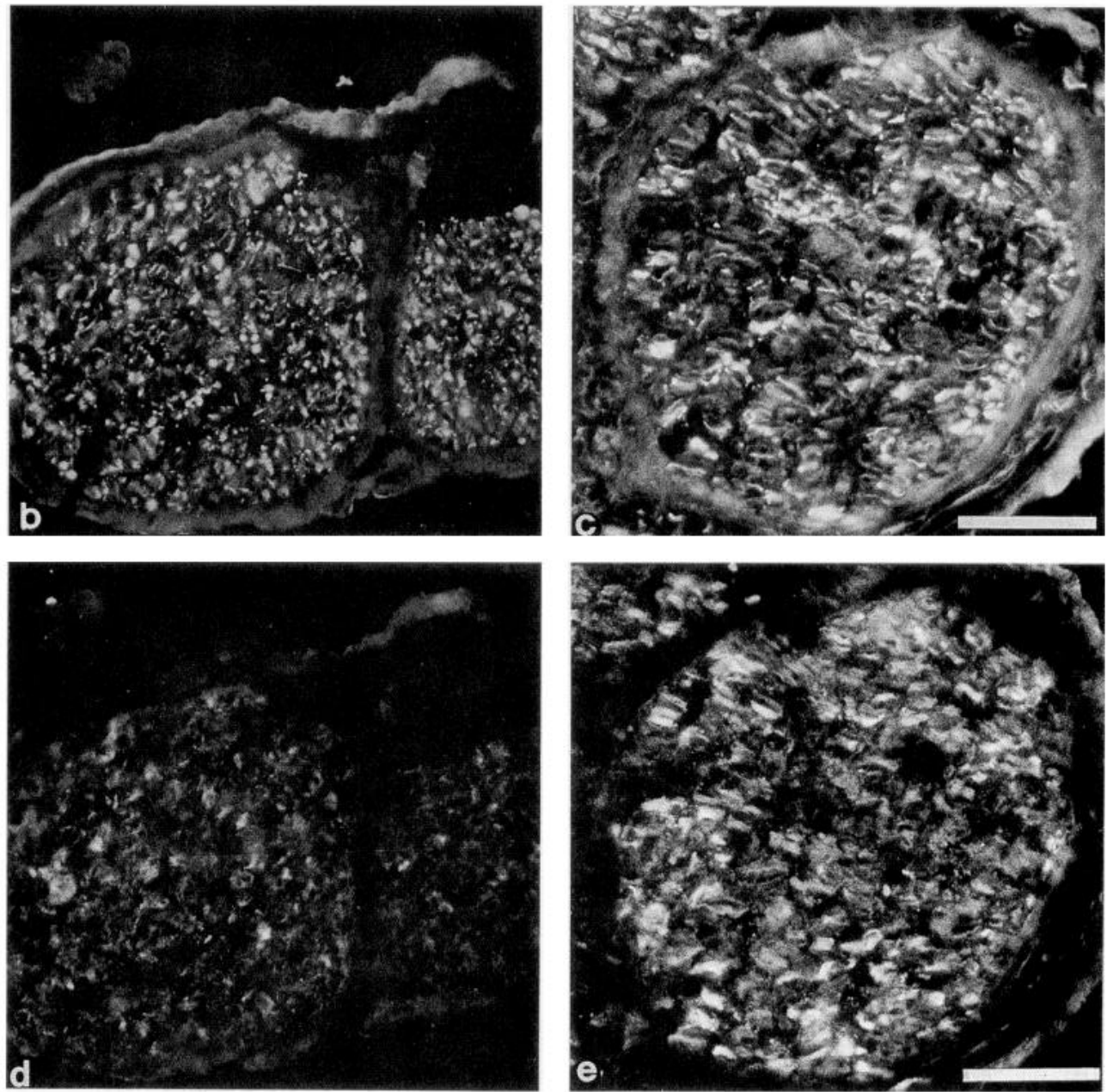

toneurons were labeled (mean $=216$ ) than in unoperated controls (mean $=173$ ). This observation suggests that excision of DRG damaged some underlying motor axons, thereby allowing spread of tracer to axons not contributing to the femoral nerve. The observation that some labeled motoneurons $($ mean $=23$ ) were found outside the normal femoral motoneuron pool is consistent with this interpretation. Transection of ventral roots in four DE animals abolished the labeling of motoneurons and did not alter the number of labeled DRG neurons.

These observations support the hypothesis that the L2 im- munoreactivity in muscle branches is almost exclusively related to Schwann cells associated with motor axons. They are consistent with previous observations that L2 immunoreactivity is predominantly expressed in myelin sheaths of ventral roots, but only scarcely in those of dorsal roots (Martini et al., 1988).

\section{Distal (DR) and proximal $(P R)$ repair of femoral nerves}

When the femoral cutaneous and muscle branches were individually transected and appropriately realigned (DR), Schwann cell-related L2 immunoreactivity was detected in six of seven 


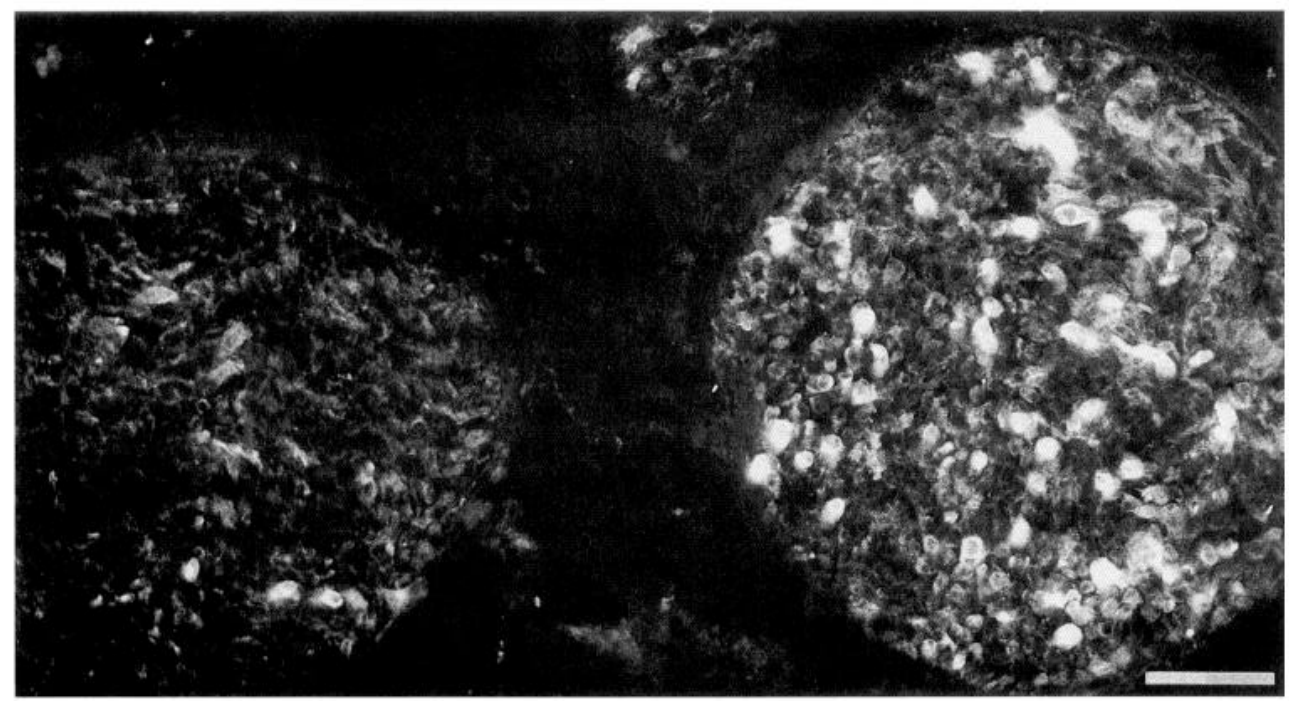

Figure 4. Immunocytological localization of $\mathrm{L} 2$ by indirect immunofluorescence on fresh-frozen sections of proximally repaired and target-deprived femoral nerves (PR-B) 4 weeks after surgery. L2 immunoreactivity is low in the cutaneous branch where only few L2-positive myelinating Schwann cells are visible (on the left), but is high in the muscle branch (on the right). Scale bar, $50 \mu \mathrm{m}$.

reinnervated muscle branches 12 weeks after the operation. The number of immunoreactive fibers was reduced to $30-50 \%$ of unoperated controls as was their diameter. In one nerve, L2 immunoreactivity was not detectable, even though myelin sheaths had formed around neurofilament-positive axons. In all experiments, the myelin sheaths of reinnervated cutaneous branches did not contain Schwann cell-related L2 immunoreactivity.

Femoral nerves were also transected and repaired proximally (PR) at a location where axons destined for muscle and cutaneous branches intermingle. Seven nerves were investigated, four after 4 weeks and three after 12 weeks, with similar results. The muscle branches of these nerves contained many L2-positive myelinating Schwann cells, while the cutaneous branches contained very few (Fig. $3 a$ ). The pattern of L2 immunoreactivity in the femoral nerve of PR animals was thus very similar to that found in nerves of DR animals. It is important to mention in this context that the lack of L2 immunoreactivity in the cutaneous branch was not the result of poor axonal regrowth into this branch. Rather, axonal regrowth was always vigorous, as revealed by the presence of more than 500 neurofilamentimmunoreactive profiles in each cutaneous nerve branch investigated. As observed in distal repairs, the muscle branches of the proximally repaired nerves contained fewer L2-positive myelinating Schwann cells than those of control nerves (3050\%; compare Figs. $2 a, 3 a$ ).

\section{Proximal repair of deafferented femoral nerves (DA-PR)}

In the rat femoral nerve, motor axons initially grow into both muscle and cutaneous branches after proximal repair (PR) (Brushart, 1990, 1993). Since this phenomenon most likely occurs in mice as well, it was unexpected to find that Schwann cellrelated L2 immunoreactivity was strongly expressed in muscle branches, but only poorly in cutaneous branches (see above). We thus examined the possibility that regrowing motor axons grow into both muscle and cutaneous branches, but are unable to upregulate L2 expression in the cutaneous branch. The ingrowth of motor axons into both muscle and cutaneous branches was investigated 4 weeks after proximal repair and deafferentation (DA-PR). Surprisingly, motor axons grew even more vigorously into cutaneous branches than into muscle branches, as revealed by the presence of neurofilament-immunoreactive pro- files (Fig. 3b,c). Double immunofluorescence with antibodies to L2 performed on the same sections confirmed that the epitope was largely confined to the muscle branch even though motor axons grew into both branches (Fig. $3 d, e$ ).

\section{Proximal repair of target-deprived nerves $(P R-B)$}

As a next step, we considered the possibility that the reinnervated muscle targets may influence the expression of $\mathrm{L} 2$ in reinnervated muscle branches, since target contact has been shown to influence the degree of myelin formation around target-innervating axons (Voyvodic, 1989). Such a target influence could explain the strong expression of L2 by motor axon-associated Schwann cells in muscle branches in contrast to the poor expression of the epitope by Schwann cells in cutaneous branches where axonal contact to skeletal muscles is unlikely. Femoral nerves were proximally transected and repaired as above (PR), but regenerating motor axons were prevented from reaching muscles (PR-B). The muscle and cutaneous branches were sutured within blocked silicon tubes to prevent escape of axons. Three animals were investigated 4 weeks after operation. In each case, L2 expression was prominent in the target-deprived muscle branches, while target-deprived cutaneous branches displayed little L2 immunoreactivity (Fig. 4), although axonal regrowth was vigorous, as revealed by the presence of 350-500 neurofilament-positive axonal profiles in the three cutaneous nerve branches investigated. Preferential expression of L 2 by Schwann cells of the muscle branch is thus independent of target innervation and must depend on specific axon-Schwann cell interactions in the nerve.

\section{Reversed distal repair (DR-R), reversed graft $(G-R)$, and graft (G)}

After proximal femoral repair (PR), innervation of cutaneous branches by motor axons did not lead to L2 expression. This phenomenon was further investigated by misdirecting motor axons into the cutaneous nerve. Reversed distal repairs (DRR) were performed in which axons of muscle branches were directed into the cutaneous branch and axons of cutaneous branches were directed into the muscle branch. Twelve weeks after surgery, significant L2 expression was found associated with only 15-25 myelinating Schwann cells of the distal cutaneous branch in three nerves. In the other four cutaneous 
Figure 5. Immunocytological localization of $\mathrm{L} 2$ by indirect immunofluorescence on fresh-frozen sections of nerves from a reversed graft (G-R; $a-$ $d$ ), and graft ( $\mathrm{G} ; e$ and $f$ ) experiment, 4 weeks after surgery. $a$, cutaneous nerve graft inserted into a muscle branch; $b$, corresponding distal muscle branch; $c$, muscle nerve graft inserted into a cutaneous branch; $d$, corresponding distal cutaneous branch; $e$, homotopic muscle nerve graft; $f$, corresponding distal segment of the muscle branch. $a$, The inserted cutaneous nerve graft innervated by axons from the muscle branch contains only few and rather weakly labeled L2-positive myelinating Schwann cells. $b$, The distal muscle branch innervated by the same axons as the cutaneous nerve graft shown in $a$ contains many L2-positive myelinating Schwann cells of high immunoreactivity. $c$, The inserted muscle nerve graft innervated by axons from cutaneous branch contains a few L2-positive myelinating Schwann cells (arrowheads). $d$, The distal cutaneous branch contains predominantly L2-positive nonmyelinating Schwann cells (arrowheads). $e$ and $f$, In homotopic muscle nerve grafts $(e) \mathrm{L} 2$ immunoreactivity is at least as high as in the corresponding distal muscle branch $(f)$, demonstrating that grafting per se does not interfere with L2 expression. Scale bar, $50 \mu \mathrm{m}$.
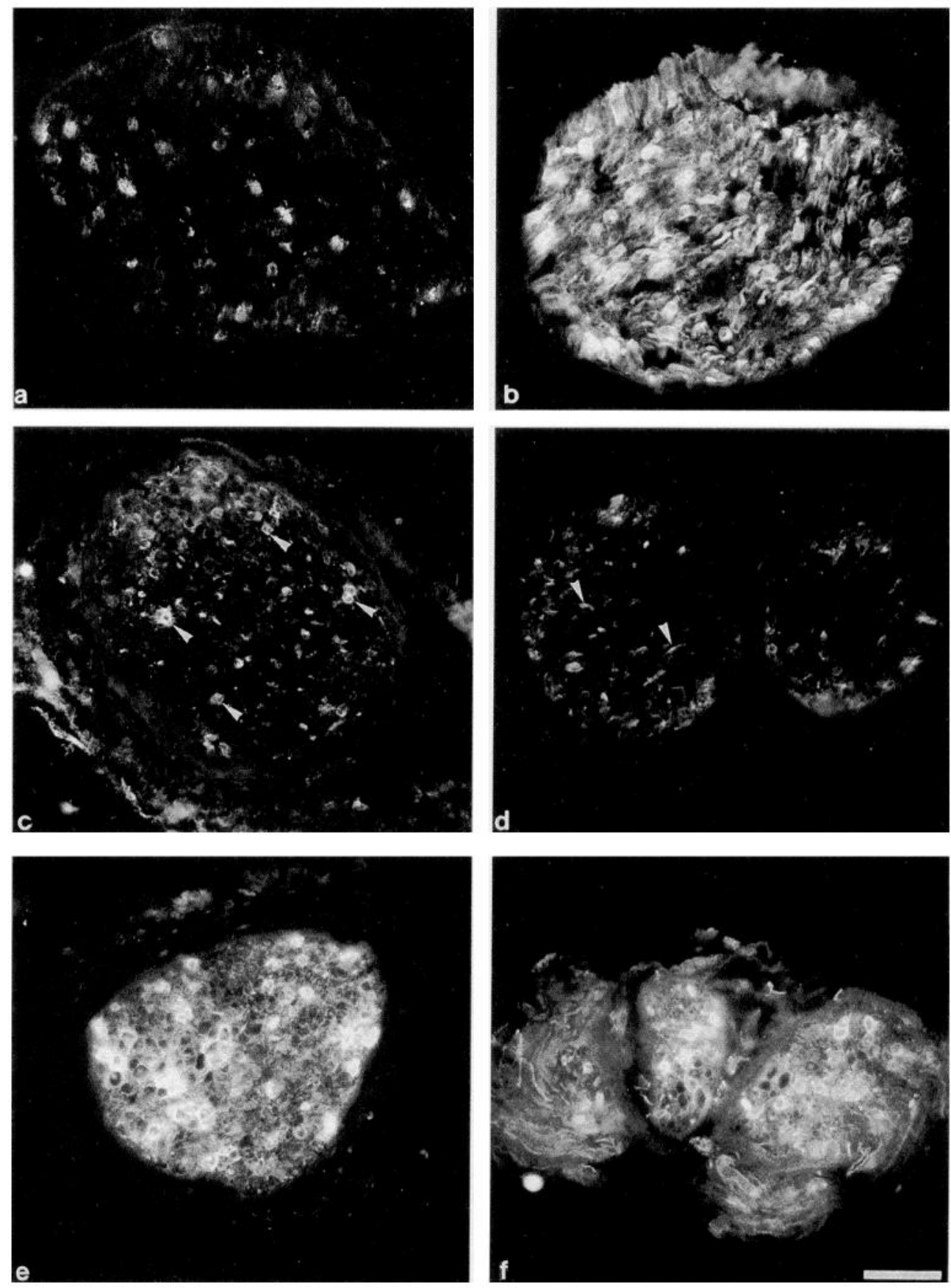

branches studied, L2 immunoreactivity was either very weak and confined to only five to nine Schwann cells, or was not detectable at all. Muscle branches reinnervated by axons of the cutaneous branches contained 10-20 myelinated and some nonmyelinated L2-positive Schwann cells as revealed by $\mathrm{L} 1 \mathrm{im}$ munoreactivity. In all cases, the distal muscle or cutaneous nerve stumps contained several hundred myelin sheaths and were strongly reinnervated, as revealed by phase-contrast microscopy and neurofilament immunoreactivity, respectively.

A particularly interesting pattern of L2 expression was seen in the reverse graft preparations (G-R). Five nerves were investigated at 4 weeks, one nerve at 8 weeks, and four nerves at 12 weeks after surgery. At all postoperative intervals, muscle nerve axons elicited detectable L2 immunoreactivity on a few
Schwann cells of inserted cutaneous nerve grafts (Fig. $5 a$, Table 1). Longer cutaneous nerve grafts $(8-10 \mathrm{~mm})$ contained more L2-positive myelin sheaths than shorter ones (3-5 mm). However, when muscle branches distal to the inserted cutaneous nerve grafts were examined, high L2 expression was found in 9 of 10 nerves. Many more L2-positive myelinating Schwann cells were found than in the adjacent cutaneous nerve grafts (Fig. $5 b$, Table 1) and these Schwann cells were more strongly labeled than those few L2-positive ones in the cutaneous branch (Fig. $5 b$ ). This is noteworthy, since the distal muscle branch was reinnervated by the same axons that had penetrated the cutaneous nerve graft, where they elicited only a poor L2 expression (compare $5 a, b$ ). In one nerve investigated 12 weeks after operation, neither the inserted cutaneous nerve graft nor the distally 


\begin{tabular}{|c|c|c|c|c|}
\hline Number of $\mathbf{L} 2+\mathrm{SCs}$ & 0 & $<10$ & $10-30$ & $>50$ \\
\hline \multicolumn{5}{|l|}{ G-R animals } \\
\hline Cutaneous $\mathrm{n}$. into muscle $\mathrm{n}$. & $1 / 10$ & $3 / 10$ & $6 / 10$ & $0 / 10$ \\
\hline Muscle $n$. into cutaneous $n$. & $7 / 10$ & $0 / 10$ & $3 / 10$ & $0 / 10$ \\
\hline Distal muscle $\mathrm{n}$ & $1 / 10$ & $0 / 10$ & $0 / 10$ & $9 / 10$ \\
\hline \multicolumn{5}{|l|}{$\mathrm{G}$ animals } \\
\hline Muscle $\mathrm{n}$. into muscle $\mathrm{n}$. & $1 / 4$ & $0 / 4$ & $0 / 4$ & $3 / 4$ \\
\hline Distal muscle $n$ & $0 / 4$ & $0 / 4$ & $0 / 4$ & $4 / 4$ \\
\hline
\end{tabular}

The number of experiments in which a certain number (e.g., 10-30) of L2-immunoreactive Schwann cells (L2 ${ }^{+} \mathrm{SCs}$ ) were counted in a given part of a nerve (e.g., distal muscle $n$.) is given as a fraction of the total numbers of experiments performed. n., nerve.

linked muscle branch was significantly L2 positive, although heavily reinnervated as revealed by neurofilament-immunoreactive profiles.

Muscle nerve grafts inserted into cutaneous branches contained few L2-positive myelinated axon-Schwann cell units or were entirely L2 negative (Fig. $5 c$, Table 1). As in the cutaneous branches of unoperated animals, weak L2 immunoreactivity was predominantly associated with nonmyelinated axonSchwann cell units in the distal parts of cutaneous branches of G-R animals and L2-positive myelinating Schwann cells were very rare (Fig. $5 d$ ).

We considered the possibility that poor L2 expression by cutaneous nerve grafts containing motor axons is a consequence of the grafting procedure. Grafts of the femoral muscle branch were therefore inserted into the contralateral muscle branch and investigated 4 weeks later $(G)$. In three of four experiments, inserted muscle nerve contained numerous, highly L2-immunoreactive myelinating Schwann cells (Fig. 5e, Table 1) indicating that grafting per se does not interfere with the capacity of Schwann cells to express L2. Muscle branches distal to the insertion were always strongly L2 positive (Fig. $5 f$, Table 1). The combined observations support the idea that muscle branch axons can induce $\mathrm{L} 2$ expression more effectively in muscle than in cutaneous branches.

The difference in L2 expression induced by motor axons in cutaneous and muscle nerve grafts could reflect a decreased axon diameter and myelination in the former. To exclude this possibility, we compared the diameters of 200 randomly selected myelinated axons in the inserted cutaneous and distal muscle branches on electron micrographs. The distribution of axon diameters (Fig. 6) was too similar in both cutaneous and muscle nerve grafts to account for the robust difference in L2 expression. Furthermore, there were no differences in frequency and overall appearance of myelin sheaths in both nerve segments and the ratios of axonal and fiber diameters were almost identical $(0.68$ for inserted cutaneous, 0.67 for distal muscle; $n=50$ for each nerve; Fig. $7 a, b$ ).

As a next step, immunoelectron microscopic studies were performed with monoclonal L2 antibodies to correlate L2 expression with myelination. L2 expression was initially analyzed by preembedding staining procedures. With this technique, only basal laminae of the L2-positive, myelinating Schwann cells were labeled. By postembedding staining, Schwann cells expressing L2 in their basal laminae could be shown to express L2 also in compact myelin and in the periaxonal space (not

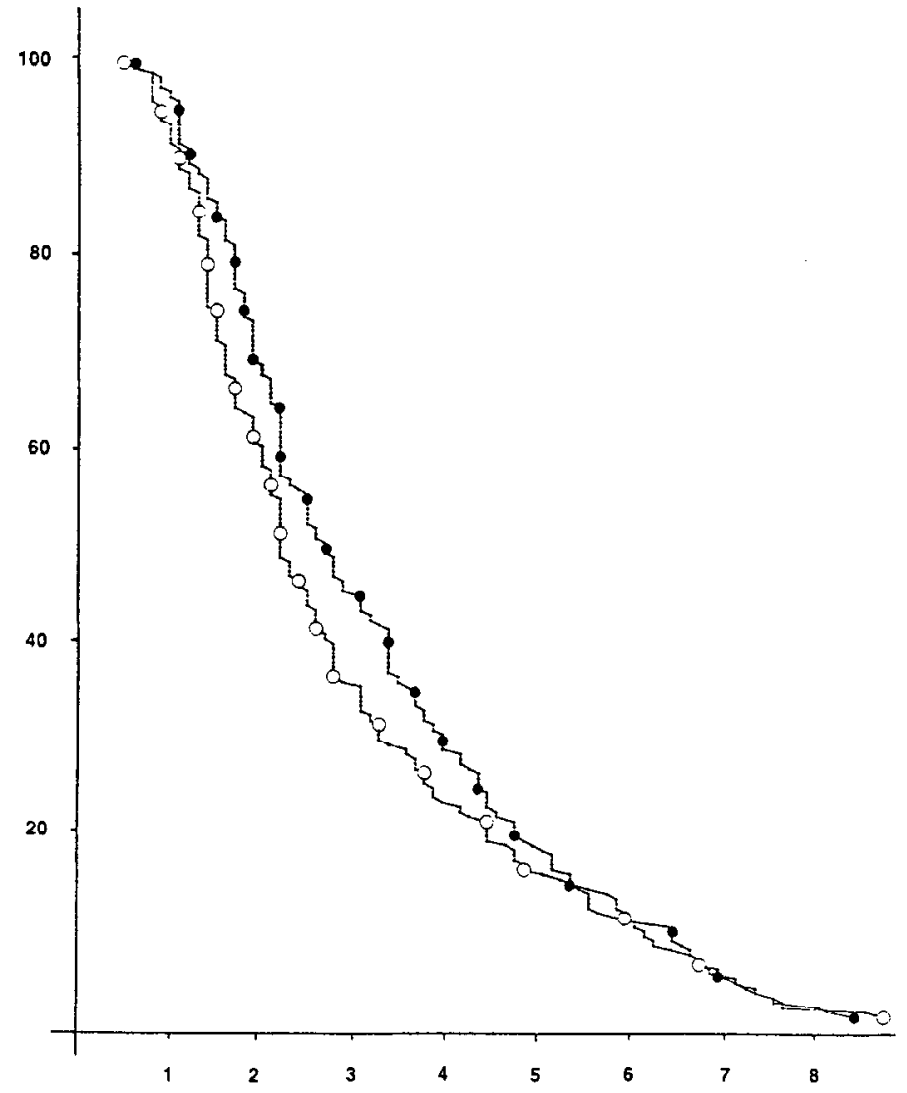

Figure 6. Diagrammatic representation of axonal calibers in inserted cutaneous (open circles) and distal muscle (solid circles) branches of a reverse graft situation (G-R). The diagram shows the percentages of axonal profiles (ordinate) with particular diameters exceeding the values given in the abscissa (in $\mu \mathrm{m}$ ). Every 10 th of the 200 values is indicated by a data point. Values are from one animal sacrificed 16 weeks after surgery. Axonal calibers are very similar in the two nerves.

shown). Since larger sections of regenerated nerves could not be evaluated by the postembedding staining technique and since the basal laminae faithfully indicated $L 2$ expression by Schwann cells, the number of L2-positive Schwann cells was scored by the preembedding technique.

Cutaneous nerve grafts were heavily myelinated 16 weeks after insertion into muscle branch (G-R), but L2 expression by myelinating Schwann cells was rare (Fig. $7 c$ ). To exclude the possibility that lack of detectable L2 immunoreactivity was due to incomplete penetration of antibodies into the nerve tissue, only areas containing $\mathrm{L} 2$-immunoreactive nonmyelinated axon Schwann cell units were investigated (Fig. $7 c$ ). Of 45 myelin sheaths scored in the close neighborhood of L2-positive nonmyelinating Schwann cells, only three were L2 positive.

In the muscle branches distal to the cutaneous nerve graft L2 immunoreactivity in myelinating Schwann cells was much more abundant than in the cutaneous nerve grafts. L2 immunoreactivity was found in about $25 \%$ of the myelinating Schwann cells and not confined to myelin sheaths of larger thickness. Myelin sheaths around axons of moderate thickness (3-4 $\mu \mathrm{m}$ ) were also stained in the distal muscle branch, whereas myelin sheaths around axons of much larger diameter were unstained in the cutaneous nerve graft (compare Fig. $7 c, d$ ).

In summary, our combined observations show that the muscle nerve-derived Schwann cells having previously expressed L2 readily express the epitope after motor axon regrowth, whereas 

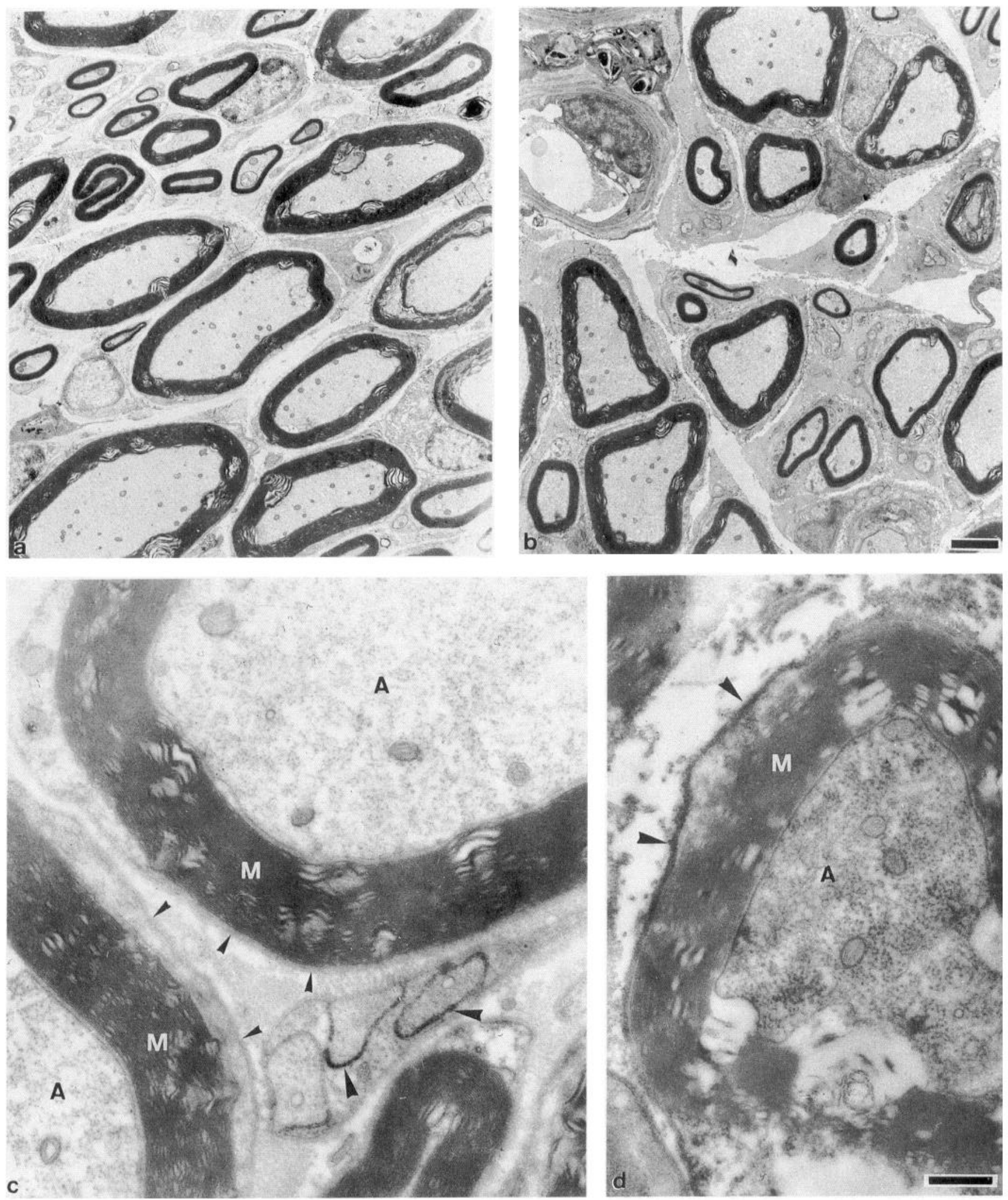

Figure 7. Conventional transmission electron microscopy of a cutaneous nerve graft inserted into a muscle nerve (a) and corresponding distal muscle branch $(b)$ and immunoelectron microscopic localization of $\mathrm{L} 2$ by preembedding staining procedures of a cutaneous nerve graft inserted into a muscle branch $(c)$ and corresponding distal muscle branch $(d)$ of a reverse graft $(\mathrm{G}-\mathrm{R})$ situation, 16 weeks after the operation. $a$ and $b$, Note the similar appearance of myelin and axonal calibers in the cutaneous nerve inserted into the muscle nerve $(a)$ and corresponding distal muscle nerve $(b) . c$, In the inserted cutaneous nerve graft innervated by axons from the muscle branch, electron-dense immunoperoxidase reaction product is confined to axon-Schwann cell contacts in nonmyelinated fibers (large arrowheads), whereas the outer aspects of the two myelinating Schwann cells around large-caliber axons are negative (small arrowheads). $A$, axon; $M$, myelin. $d$, In the distal muscle branch, electron-dense immunoperoxidase reaction product is visible at the outer aspect of a myelinating Schwann cell (arrowheads). $A$, axon; $M$, myelin. Scale bars: $a$ and $b, 2 \mu$ m; $c$ and $d$, $0.5 \mu \mathrm{m}$. 

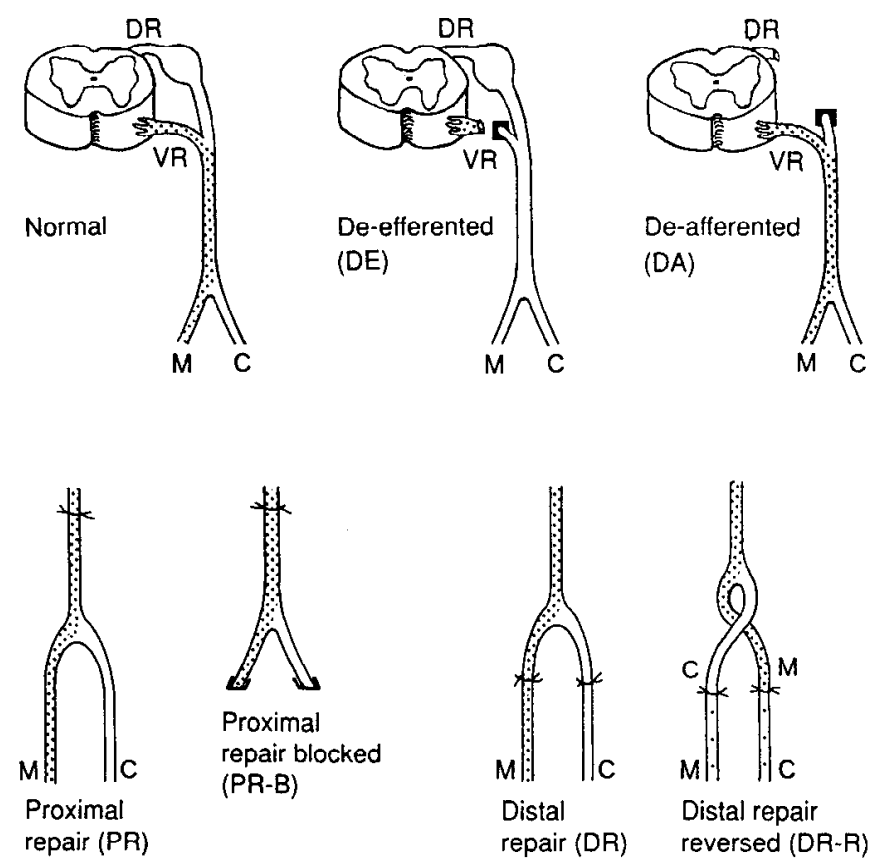
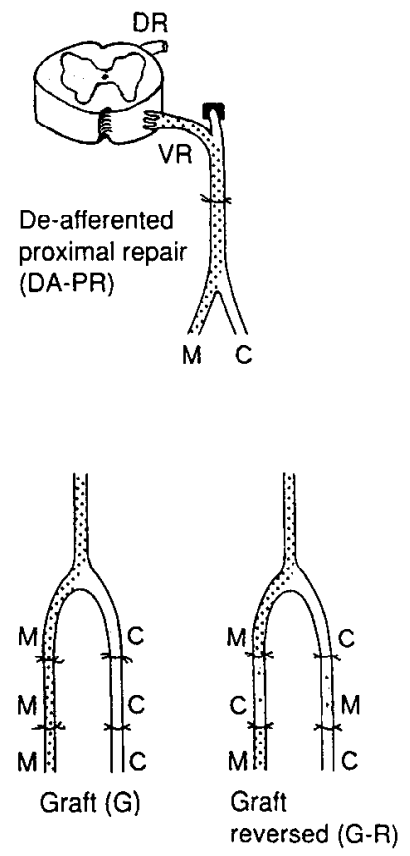

Figure 8. Expression of the L2 carbohydrate epitope in unlesioned (Normal) and experimentally manipulated femoral nerves, 4-16 weeks after surgery. Stippling represents L2 immunoreactivity by myelinating Schwann cells in the femoral nerve. In unoperated nerves (Normal), L2immunoreactive myelinating Schwann cells indicate the route taken by the motor axons innervating the muscle $(M)$, but not the cutaneous branch $(C)$ of the femoral nerve. This immunoreactivity disappears after deefferentation $(D E)$, but not after deafferentation $(D A)$, indicating the importance of motor axons for L2 immunoreactivity on myelinating Schwann cells. However, the presence of motor axons alone is not sufficient for L2 expression by myelinating Schwann cells under nerve injury conditions. In all kinds of proximal repairs $(D A-P R, P R, P R-B)$, the muscle branch is the only branch with high L2 immunoreactivity, although motor axons reinnervate the cutaneous branch as well. Similariy, in reverse distal repair $(D R-R)$ and reverse graft $(G-R)$ experiments, motor axons from the muscle branch only poorly induce $\mathrm{L} 2$ in cutaneous branches, whereas L2 immunoreactivity is strong in muscle nerve-derived Schwann cells of distal repairs $(D R)$, graft $(G)$, and reverse graft $(G-R)$ experiments.

Schwann cells from cutaneous branch previously associated with sensory axons show a much weaker tendency to express L2, even when challenged with motor axons and forming myelin sheaths around them. These findings are schematically summarized in Figure 8.

\section{Discussion}

This study was designed to evaluate the axonal influence on the expression of the L2 carbohydrate epitope by Schwann cells. The population of axons associated with Schwann cells that normally express $\mathrm{L} 2$ was investigated by preparing deafferented and deefferented femoral nerves. Myelinating Schwann cells that expressed L2 were almost always associated with motor axons. Our present observations agree with a previous study in which myelinating Schwann cells of the ventral root expressed the L2 carbohydrate, but those of the dorsal root were predominantly L2 negative (Martini et al., 1988). This modality-specific expression suggests that particular axonal qualities may trigger Schwann cells to express L2. To explore this possibility further, we investigated L2 expression by Schwann cells of muscle and cutaneous nerves when challenged by motor or sensory axons.

When the femoral nerve was lesioned proximally, at a location where axons destined for cutaneous and muscle branches intermingle, axons reinnervated Schwann cell tubes destined for both branches. However, L2 expression was confined to the muscle branch. This was also the case after repair in deafferented animals (DA-PR), where regrowing motor axons were found in both muscle and cutaneous branches, but L2 expression was limited to the muscle branch. Similarly, when cutaneous nerve grafts were inserted into the muscle branch, regrowth of muscle nerve axons led to only weak L2 expression in the cutaneous nerve graft, but to high $\mathrm{L} 2$ expression in the muscle branch distal to the graft.

Our combined observations suggest a much more active role for the Schwann cell in determining its phenotype than previously anticipated. Two distinct types of myelinating Schwann cells can be distinguished by their response to regenerating axons: the one previously associated with motor axons readily expresses L2; the other previously associated with sensory axons shows a much weaker tendency to express L2, even when challenged with motor axons. This obscrvation is noteworthy, since denervated Schwann cells are thought to regain their functional pluripotency during Wallerian degeneration, until the regrowing axons determine their redifferentiation (Weinberg and Spencer, 1975; Aguayo et al., 1976a,b). This view is in agreement with our observation that the rate of myelination and the size of the axonal profiles are very similar in both distal muscle and inserted cutaneous branches, although the latter contains many more nonmyelinating Schwann cells when innervated by its appropriate axonal partners (Giese et al., 1992; Martini et al., 1992). Our results, however, show that previously motor axonassociated Schwann cells retain some of their acquired properties and express the L2 carbohydrate epitope more effectively than Schwann cells that have previously myelinated sensory axons, thereby appearing to remember their previous axonal association.

L2 expression requires ongoing contact between motor axon and Schwann cells. After denervation, previously motor axon- 
associated L2-positive Schwann cells downregulate L2 expression within 2-3 weeks (Martini et al., 1992). In the present study, permanently deefferented nerves were L2 negative when examined in the fourth postoperative week. Similarly, Schwann cells harvested from adult animals lose their L2 immunoreactivity in culture (Martini, unpublished observation). Furthermore, Schwann cells of muscle nerves express the epitope poorly when reinnervated by inappropriate axons from the cutaneous branch. The observed strong immunoreactivity on previously muscle nerve-resident Schwann cells is thus not the result of a continuous L2 expression, but is instead a motor axon-dependent upregulation of L2 in Schwann cells that would have otherwise become $\mathrm{L} 2$ negative.

The mechanisms by which regenerating motor axons may interact with appropriate Schwann cells to induce L2 expression are unknown. They may depend on both receptors and their corresponding ligands on the interacting partner cells. The instructive signal(s) from motor axons could be diffusible factors or cell surface ligands that interact with cell surface receptors on appropriate Schwann cells. Once these receptors are activated, second-messenger pathways could lead to expression of the $\mathrm{L} 2$ epitope. This model implies that the presence of just one component is not sufficient for L2 expression: sensory axons cannot evoke high levels of L2 expression in Schwann cells of the muscle branch nor can motor axons induce it strongly in the cutaneous branch. Further experiments will be needed to identify the inducing ligand(s) of the motor axon and the corresponding receptor on the receiving Schwann cell.

L2 expression was significantly lower in reinnervated femoral nerves than in unlesioned controls. Reinnervated muscle branches contained only $30-50 \%$ of the normally occurring L2immunoreactive Schwann cells. To some degree, this must reflect failure of motoneurons to reinnervate the periphery (Brushart, 1993). However, this finding can also be explained if significant L2 expression is obtained only when motor axons reinnervate Schwann cells that were previously associated with motor axons. In the reinnervated muscle branch, not all previously motor axon-associated Schwann cells are likely to be reinnervated by motor axons; some will be reinnervated by muscle afferents, and will not be stimulated to express L2. Furthermore, Schwann cells once innervated by muscle afferents can be reinnervated by motor axons, again resulting in poor L2 expression. Both of these possibilities will result in poor or absent L2 upregulation and reduce the total number of L2immunoreactive Schwann cclls in the rcinnervated muscle branch.

Modification of axonal properties by Schwann cells has been observed previously in other model systems. When dorsal root ganglion neurons are cocultured with Schwann cells, myelination influences neurite diameter (Windebank et al., 1985). Association of axons from wild-type mice with Schwann cells of the hypomyelinating mulant Trembler alters the volume of slow axonal transport, the speed of axonal regrowth, the phosphorylation of intermediate filaments, and axonal diameter (Aguayo et al., 1977; de Waegh and Brady, 1990, 1991; de Waegh et al., 1992). Together, these observations strongly modify the view that neuronal processes are always the dominating partner in the alliance between neurons and glial cells.

Schwann cell-mediated L2 expression may influence preferential reinnervation of muscle nerves by regenerating motor axons (Brushart, 1988, 1990, 1993). When the rat femoral nerve is transected and repaired proximally, where muscle and cuta- neous fibers intermingle, regrowth of motor axons into the muscle and cutaneous branches is initially random, with motor axons projecting collaterals with equal frequency into both branches. Specificity is then generated by pruning motor axon collaterals from the cutaneous nerve, while maintaining those in the muscle nerve (Brushart, 1990). Collateral pruning occurs even without target contact, suggesting a crucial role for axon-Schwann cell interactions (Brushart, 1990, 1993). Preferential L2 expression by previously motor axon-associated Schwann cells may provide the molecular basis for selective preservation of motor axon collaterals in the muscle branch. This possibility is supported by the finding that Schwann cell-derived L2 fosters neurite outgrowth from motor neurons in vitro (Martini et al., 1992). L2 may thus convey a beneficial signal for outgrowth or survival to the axons, providing correctly growing motor axon collaterals with a selective advantage over those in the inappropriate, L2negative pathway. This mechanism is consistent with the "sibling neurite bias hypothesis," which implies that axon collaterals compete for survival by biasing each others' fate during growth into environments of different beneficial qualities (Smalheiser and Crain, 1984; Goldberg and Schacher, 1987). Thus, motor axons might be capable of creating their favorable L2 carbohydrate environment by recalling their instructive signals from their appropriate glial partners, the previously motor axon-associated Schwann cells.

\section{References}

Aguayo AJ, Charron L, Bray GM (1976a) Potential of Schwann cells from unmyelinated nerves to produce myelin: a quantitative ultrastructural and radiographic study. J Neurocytol 5:565-573.

Aguayo AJ, Epps J, Charron L, Bray GM (1976b) Multipotentiality of Schwann cells in cross-anastomosed and grafted myelinated and unmyelinated nerves: quantitative microscopy and radioautography. Brain Res 104:1-20.

Aguayo AJ, Attiwell M, Trecarten J, Perkins S, Bray GM (1977) Abnormal myelination in transplanted Trembler mouse Schwann cells. Nature 265:73-74.

Bedi KS, Winter J, Berry M, Cohen J (1992) Adult rat dorsal root ganglion neurons extend neurites on predegenerated but not on normal peripheral nerves in vilro. Eur J Neurosci 4:193-200.

Bieber F (1988) Biotinylierung monoklonaler Antikörper. In: Monoklonale Antikörper, Herstellung und Charakterisierung (Peters JH, Baumgarten H, ed), pp 299-302.

Brown MC, Perry VH, Lunn ER, Gordon S, Heumann R (1991) Macrophage dependence of peripheral sensory nerve regeneration: possible involvement of nerve growth factor. Neuron 6:359-370.

Brown MC, Lunn ER, Perry VH (1992) Consequences of slow Wallerian degeneration for regenerating motor and sensory axons. J Neurobiol 23:521-536.

Brushart TM (1988) Preferential reinnervation of motor nerves by regenerating motor axons. J Neurosci 8:1026-1031.

Brushart TM (1990) Preferential motor reinnervation: a sequential double-labeling study. Rest Neurol Neurosci 1:281-287.

Brushart TM (1993) Motor axons preferentially reinnervate motor pathways. J Neurosci 13:2730-2738.

de Waegh S, Brady ST (1990) Altered slow axonal transport and regeneration in a myelin-deficient mutant mouse: the Trembler as an in vivo model for Schwann cell-axon interactions. J Neurosci 10:18551865.

de Waegh SM, Brady ST (1991) Local control of axonal properties by Schwann cells: neurofilaments and axonal transport in homologous and heterologous nerve grafts. J Neurosci Res 30:201-212.

de Waegh SM, Lee VM-Y, Brady ST (1992) Local modulation of neurofilament phosphorylation, axonal caliber, and slow axonal transport by myelinating Schwann cells. Cell 68:451-463.

Fahrig T, Schmitz B, Weber D, Kücherer-Ehret A, Faissner A, Schachner M (1990) Two monoclonal antibodies recognizing carbohydrate epitopes on neural adhesion molecules interfere with cell interactions. Eur J Neurosci 2:153-161. 
Giese KP, Martini R, Lemke G, Soriano P, Schachner M (1992) Mouse $\mathrm{P0}$ gene disruption leads to hypomyelination, abnormal expression of recognition molecules, and degeneration of myelin and axons. Cell $71: 565-576$.

Glass JD, Brushart TM, George EB, Griffin JW (1993) Prolonged survival of transected nerve fibres in C57BL/Ola mice is an intrinsic characteristic of the axon. J Neurocytol 22:311-321.

Goldberg DJ, Schacher S (1987) Differential growth of the branches of a regenerating bifurcate axon is associated with differential axonal transport of organelles. Dev Biol 124:35-40.

Jessen KR, Mirsky R (1992) Schwann cells: early lineage, regulation of proliferation and control of myelin formation. Curr Opin Neurobiol 2:575-581.

Kruse J, Mailhammer R, Wernecke H, Faissner A, Sommer I, Goridis C, Schachner M (1984) Neural cell adhesion molecules BSP-2 and L1 share a common carbohydrate moiety recognized by monoclonal antibodies L2 and HNK-1. Nature 311:153-155.

Lunn ER, Perry VH, Brown MC, Rosen H, Gordon S (1989) Absence of Wallerian degeneration does not hinder regeneration in peripheral nerve. Eur J Neurosci 1:27-33.

Martini R (1994) Expression and functional roles of neural cell surface molecules and extracellular matrix components during development and regeneration of peripheral nerves. J Neurocytol 23:1-28.

Martini R, Schachner M (1986) Immunoelectron microscopic localization of neural cell adhesion molecules (L1, N-CAM, and MAG) and their shared carbohydrate epitope and myelin basic protein in developing sciatic nerve. J Cell Biol 103:2439-2448.

Martini R, Schachner M (1988) Immunoelectron microscopic localization of neural cell adhesion molecules (L1, N-CAM, and myelinassociated glycoprotein) in regenerating adult mouse sciatic nerve. $\mathrm{J}$ Cell Biol 106:1735-1746.

Martini R, Schachner M (1991) Complex expression pattern of tenascin during innervation of the posterior limb buds of the developing chicken. J Neurosci Res 28:261-279.

Martini R, Bollensen E, Schachner M (1988) Immunocytological localization of the major peripheral nervous system glycoprotein PO and the L2/HNK-1 and L3 carbohydrate structures in developing and adult mouse sciatic nerve. Dev Biol 129:330-338.
Martini R, Schachner M, Faissner A (1990) Enhanced expression of the extracellular matrix molecule J1/tenascin in the regenerating adult mouse sciatic nerve. J Neurocytol 19:601-616.

Martini R, Xin Y, Schmitz B, Schachner M (1992) The L2/HNK-1 carbohydrate epitope is involved in the preferential outgrowth of motor neurons on ventral roots and motor nerves. Eur J Neurosci $4: 628-639$.

Nieke J, Schachner M (1985) Expression of the neural cell adhesion molecules L1 and N-CAM and their common carbohydrate epitope L2/HNK-1 during development and after transection of mouse sciatic nerve. Differentiation 30:141-151.

Peyronnard JM, Charron LF, Lavoie J, Messier JP (1986) Motor, sympathetic and sensory innervation of rat skeletal muscles. Brain Res. 373:288-302.

Rathjen FG, Schachner M (1984) Immunocytological and biochemical characterization of a new neuronal cell surface component ( $\mathrm{Ll}$ antigen) which is involved in cell adhesion. EMBO J 3:1-10.

Schmalbruch $\mathrm{H}$ (1986) Fiber composition of the rat sciatic nerve. Anat $\operatorname{Rec} 215: 71-81$.

Seilheimer B, Persohn E, Schachner M (1989) Antibodies to the L1 adhesion molecule inhibit Schwann cell ensheathment of neurons in vitro. J Cell Biol 109:3095-3103.

Smalheiser NR, Crain SM (1984) The possible role of "sibling neurite bias" in the coordination of ncurite extension, branching, and survival. J Neurobiol 15:517-529.

Voyvodic JT (1989) Target size regulates calibre and myelination of sympathetic axons. Nature 342:430-433.

Weinberg HJ, Spencer, PS (1975) Studies on the control of myelinogenesis. I. Myelination of regenerating axons after entry into a foreign unmyelinated nerve. J Neurocytol 4:395-418.

Windebank AJ, Wood P, Bunge RP, Dyck PJ (1985) Myelination determines the caliber of dorsal root ganglions in culture. J Neurosci 5:1563-1569.

Wood PM, Schachner M, Bunge RP (1990) Inhibition of Schwann cell myelination in vitro by antibody to the $\mathrm{Ll}$ adhesion molecule. $\mathrm{J}$ Neurosci 10:3635-3645. 